\title{
Chenang Beach and its Crowding Capacity: A Malaysian Perspective
}

\author{
Diana Mohamad ${ }^{1}$, Azizan Marzuki ${ }^{2}$ \\ ${ }^{1}$ Sustainable Tourism Research Cluster, Universiti Sains Malaysia, 11800 Penang, Malaysia \\ ${ }^{2}$ School of Housing, Building and Planning, Universiti Sains Malaysia, 11800 Penang, Malaysia
}

\begin{abstract}
This working paper focuses in enjoyment factors, specifically: number of beach users, perceived maximum number of beach users accepted, perceived maximum number of beach users that affects the tourism experience and perceived maximum number of beach users that affects the beach quality. At a deeper extent, the evaluation is categorized by number of visitation, visitation motivations, and Chenang Island's push and pull factors. Relationships between variables were assessed using a two-phase evaluation framework where interestingly, only one demographic factor works with all the studied independent variables. It is also learned that the density of an area (number of people seen) is considered as an accepted crowding factor, as opposed to this working paper scope (experienced crowding). A unique relationship was observed for crowding level, and visitation satisfaction level and overall evaluation of Chenang beach quality. This working paper further supports the previous literature on the significance of beach carrying capacity management and it is learned that the idea of crowding standard is interlinks with 'gender, 'time spend' and 'number of boaters'. From findings, this working paper envisages the preferences polar exchange where this should be of interest to tourism-related personnel. It is within this working paper interest to highlight the pressing need in brandishing the image of Chenang Beach. This is to ensure that Chenang Beach, as a field, is maintaining its importance and popularity.
\end{abstract}

\section{Introduction}

With reference to Lupke-Schwarz [1], engagement in tourism industry was first started in the $18^{\text {th }}$ century by the aristocrats who travel for fun and by the pilgrims who travel for salvation purpose. Overtime, tourism industry is quickly accepted and adopted owing to its financial beneficial [2], and more importantly, due to high disposable income and considerable amount of leisure time available. The tourism studies typology can be broadly encapsulated into categories of nature-based (for instance ecotourism and green tourism) and alternative-based (for example heritage tourism and medical tourism). As a field, beaches have been long recognized as one of the nature-based tourism attraction pillars. Apart from the economic development means, beaches are being utilized as an education awareness tool by the appointed bodies [3]. Therefore, changes face by beaches with regards to tourism-trends-demand-and-beaches-supply chain is stimulating the scholars' concerns in relation to the beaches carrying capacity. Having said this, the beach tourism can be viewed from the following interrelated questions: is beach tourism something that is continuously planned? Or, is beach tourism 
something that is planned yet unable to keep score with its surroundings? In light of this situation, this working paper is designed to seek the tourists' perception towards crowding level in the island, looking at their experience of tourism development in Chenang Beach, Langkawi Island, Malaysia.

\section{Literature Review}

The tourism industry, an entity that was once considered as the domain of the rich, is governs by three stakeholders (services providers, tourism consumers and the government). Tourism industry has undergone the transformation process where the paradigm shifted from traditional mass production to automobile-based mass tourism production [4]. To [2], the existing tourism industry paradigm is showing a constant movement towards tailor-made preference. As a field that is traditionally focused on foundation issues (conceptually and methodologically), the industry has started pursuing the pragmatic solutions to resource management [5]. [6] calls the attention to the following: 'But all conservation of wilderness is self-defeating, for to cherish we must see and fondle, and when enough have seen and fondled, there is no wilderness left to cherish'. The previous statement echoes the heightened concerns of resources management, by which, closely interconnects with the limits of acceptable change (LAC) planning system [7]. Further compounding this is the unavoidable changes contributed by the development of tourism industry. Thus, the sustainability concept plays a crucial part in balancing these two spheres. Here, the power of determining the crowding standard comes into power. The initial movement towards crowding awareness can be related to sustainable tourism development concept where principally, this concept calls for the human-resources long-term viability relationship [7]. This implies the human rights to take pleasure in tourism, at the expense of resources (and site) planning. As crowding covers various disciplines (for instance social, economy and environment), perception and acceptance towards crowding are a unique representative of one's subjective judgment and reaction to density [8]. To [3], crowding '...is not simply related to the density of people in a given area, but involves a cognitive evaluation of the social and resource conditions encountered by the recreationist'. [9] who define crowding as '...a negative evaluation of use levels or number of encounters with other users', categorize crowding into crowding-averse and crowding-tolerant segments. The paradigm shift between crowding-averse and crowding-tolerant, to a certain extent, is influenced by one's psychology stability in accepting changes of the surroundings. For instance, the difference in crowding standard between regional rural and urban visitors of a national park is fairly interlinks with the use displacement in addition to past experience and nous [10]. At a greater extent, the use displacement is also addressing the effect of surroundings (types and density) towards crowding standard of a site. For example, crowding standard is higher for land-based site when compared to water-based site given the uncomplicated nature of social interaction between individuals [3].

From the perspective of anticipation, it is learned that crowding might be handled (to a certain extent) by understanding the awareness level, with specific reference to time management and decision-making. [11] who envisage awareness level as an important factor of timing preference potential, state the following: 'Understanding individuals' anticipation of crowding [of which, influenced by their awareness level] is important because such anticipation may have a significant influence on individual visit timing decisions and thereby also on crowding distribution itself'. [12] discusses [11] statement at a deeper level by highlighting issue of determining the standard level of individuals' interaction (socially and physically), by which shall be viewed from the perspective of potential and accepted crowding standard. Interestingly, [13] bring forward the potential of 'producing' crowding which may be brought upon by the site's popularity as well as the excellent quality of tourism facilities. In cases of nature-based tourism, concerns toward crowding phenomenon are '...lower when encountering one large party of users than multiple small parties' [14]. Therefore, reaction towards crowding may be envisaged as the complex chain of social, psychological and situational factors; of which, further intrigued by an individual familiarization level towards and usage level of a site. Based on the discussion, this suggests the need to assess the perceived crowding level of a site with limited immobile resources by addressing past experience, nous and acceptance level. 


\section{Research Methods}

This working paper is motivated from the second author's ongoing social capacity carrying project which focuses on searching the limitation of the currently applied social carrying capacity barometers. More specifically, this paper addresses the importance of understanding the visitors of Chenang Beach perception towards crowding issue, from the perspective of their tourism experience. Other than increasing in tourists arrival, Chenang Beach is also facing threats from the development of man-made structures, of which, may further impose limitation on its limited immobile resource carrying capacity. Targeting the tourists with minimum age of 18, data collection was done in March 2014 (within twoweek timeframe) by employing the self-administered questionnaire survey method. The data collection instrument gathers information on demographic profile (age, gender, income, marital status, education level, and occupation), tourism plan (travel companion, number of visits, visitation preferences, tourism activity engagement and length of stay) and perception towards crowding (accepted crowding level, tolerated crowding level and experienced crowding level). The instrument was tested for validity and reliability and as a result, minor amendments were made to the sentences structure and the crowding-related questions were changed into close- and open-ended based. Of 380 questionnaires distributed to the Chenang Beach visitors, 359 usable questionnaires were retrieved back and this amount to $94.47 \%$ of response rate.

\section{Research Findings}

The first part of this section addresses the preliminary findings of demographic profile (Table 1) and visitation purpose (Table 2). Whilst, the second part exhibits observation results on crowding level in Chenang Beach. Table 1 indicates: [1] female respondents contributed to $61.56 \%$ of total respondents, with respondents aged $25-44$ amount to $54.30 \%$, [2] $59.89 \%$ of total respondents is international tourists and respondents aged 25-44 dominated 53.02\%, [3] educated tourists' population with $62.40 \%$ are higher education institutions' graduates, [4] married respondents are slightly fewer (43.45\%) than single respondents (44.01\%) and [5] adult tourists (aged 25 to 44) are the dominant for all categories. Table 2 highlights the Chenang Beach high popularity where $68.25 \%$ of total respondents are loyal visitors in addition to $51.81 \%$ respondents spent more than 3 hours during the visitation. In addition, the adult tourists' were observed to favour the nature attributes, compared to the other groups who chose facilities attributes. More importantly, results indicate the dominant of positive satisfaction level (62.95\%) compared to $20.89 \%$ respondents who dissatisfied with their visitation to Chenang Beach.

Table 1. Respondents' Profile

\begin{tabular}{llccc} 
& & \multicolumn{3}{c}{ Age group } \\
Gender & Male & $\mathbf{1 8 - 2 4}$ & $\mathbf{2 5 - 4 4}$ & $>\mathbf{4 5}$ \\
& Female & 44 & 71 & 23 \\
Nationality & Malaysian & 48 & 120 & 53 \\
& International & 38 & 77 & 29 \\
Education & No formal education & 54 & 114 & 47 \\
level & Primary education & 14 & 10 & 1 \\
& Secondary education & 14 & 10 & 4 \\
& Tertiary education & 48 & 43 & 23 \\
Marital & Single & 70 & 70 & 48 \\
status & Married & 13 & 96 & 47 \\
& Others & 9 & 25 & 11
\end{tabular}


Table 2. Visitation Profile

\begin{tabular}{llccc} 
& & \multicolumn{3}{c}{ Age group } \\
Visitor type & First time & $\mathbf{1 8 - 2 4}$ & $\mathbf{2 5 - 4 4}$ & $\mathbf{> 4 5}$ \\
& Loyal visitor & 35 & 69 & 28 \\
Time spend & Less than 3 hours & 51 & 122 & 66 \\
& More than 3 hours & 41 & 94 & 25 \\
Favoured & Facilities & 39 & 67 & 29 \\
attributes & Nature & 21 & 54 & 27 \\
& Location & 32 & 70 & 20 \\
Overall & Dissatisfied & 23 & 38 & 14 \\
satisfaction & Neither & 15 & 31 & 12 \\
& Satisfied & 54 & 122 & 50
\end{tabular}

The second part of this section tested the dependent (number of people seen, maximum number of people to see, enjoyment level, opportunity to escape crowd, water activities and number of boaters) and independent (age, gender, visitor type and time spend) variables. Correlations between variables exhibit the following patterns: [1] low strength between IVs with the highest result recorded by 'visitor type-time spend' ( $r=.189, \mathrm{n}=359, p .000)$, [2] low strength between DVs and IVs with the highest result presented by 'gender-perceived crowd' $(r=.207, \mathrm{n}=359, p .000)$ and [3] only 1 medium strength observed for water activities-number of boaters $(r=.680, \mathrm{n}=359, p .000)$. The correlation results are supported by the KMO and Bartlett's Test value (.523, $p .000)$. Excluding 'age' and 'gender', the extraction values range between $37.20 \%$ (time spend) and $83.10 \%$ (water activities). More specifically, excluding 'time spend', all factors recorded higher than $50.00 \%$ extraction value. It is interesting to find that despite the near-normal distribution pattern (Table 2), the extraction value reveals that 'time spend' is slightly poor explained by other variables. This is in contrast with Inglis et al. [3] and Han et al.'s [11] findings who accentuated on time planning. Out of 9, 4 variables were extracted (Table 3) with only a slight difference in the percent of variance (component 1: 19.932\%, component 2: $15.723 \%$, component 3: $12.461 \%$ and component $4: 11.701 \%$ ). Within this paper scope, the bold variables can be categorized as follows: component 1 is perceived crowding, component 2 is accepted crowding and component 3 is experienced crowding. Meanwhile, component 4 can be defined for tourist characteristic.

From Table 4, in the context of analysis between IVs and DVs, it is learned that only 'gender' is significantly related to IVs while none of the IVs was found significant with 'water activities'. Additionally, 'number of people seen' is significant with all IVs except for 'age'. Here, it can be said that 'gender' is the dominant barometer when assessing the crowding standard. In cases of analysis between DVs, Table 3 shows that 'number of people seen' and 'opportunity to escape crowd' were also significant with the other DVs. Of importance, 'number of people seen' was negatively significant for accepted crowding factor (maximum number of people to see) and the same result was observed for 'opportunity to escape crowd' ('number of people seen' and 'maximum number of people to see'). From the perspective of 'maximum number of people to see', it can be said that respondents fall under the crowding-averse category [10]. However, from respondents are interchange between crowding-averse and crowding-tolerant when analysed from the opportunity to escape crowd' and 'enjoyment level' point of views. Further observation reveals several interesting results. It is learned that perceived crowding standard is related to the density of the area ('number of people seen' and 'maximum number of people to see'), which are defined for the ease of comfort. The results however, are in contrast to the $t$ value of 'enjoyment level-maximum number of people to see' relationship (-18.706). Surprisingly, despite the results presented in Table 3, 'water activities' recorded a slightly lower $t$ value compared to 'number of boaters'. In addition, despite the results 
presented in Tables 3 and 4, results of regression analysis (between each IV and all DVs) indicate a notably low explanation percentage (not more than $7.00 \%$ ).

Table 3. Rotated Component Matrix

\begin{tabular}{lcccc} 
& \multicolumn{4}{c}{ Component } \\
& 1 & 2 & \multicolumn{1}{l}{3} & \multicolumn{1}{l}{4} \\
Visitor type & .057 & .038 & .101 &. $\mathbf{7 2 1}$ \\
Time spend & -.065 & .327 & .340 & .381 \\
Number of people see & .102 &. $\mathbf{7 5 3}$ & .042 & .249 \\
Enjoyment level & -.269 & .035 &. $\mathbf{6 8 5}$ & .021 \\
Max number of people to see & -.102 &. $\mathbf{7 5 9}$ & -.028 & -.317 \\
Opportunity to escape crowd & .236 & -.034 & $\mathbf{. 6 6 6}$ & -.013 \\
Water activities & $\mathbf{. 9 0 7}$ & .018 & .056 & .068 \\
Number of boaters & $\mathbf{. 8 8 9}$ & -.019 & -.072 & -.017
\end{tabular}

Extraction Method: Principal Component Analysis.

Rotation Method: Varimax with Kaiser Normalization.

a. Rotation converged in 6 iterations.

Table 4. Paired T-test results.

$\begin{array}{ccc}\text { Gender } & \text { Number of people seen } & \text { Results } \\ & \text { Enjoyment level } & t=-.052, \mathrm{df}=356, p .959 \\ \text { Age } & \text { Opportunity to escape crowd } & t=-3.991, \mathrm{df}=356, p .000 \\ \text { Visitor type } & \text { Number of boaters } & t=-2.011, \mathrm{df}=356, p .045 \\ & \text { Enjoyment level } & t=-2.564, \mathrm{df}=357, p .011 \\ \text { Time spend } & \text { Number of people seen } & t=2.124, \mathrm{df}=357, p .034 \\ \text { Number of } & \text { Opportunity to escape crowd } & t=2.336, \mathrm{df}=357, p .020 \\ \text { people seen } & \text { Number of people seen } & t=-2.702, \mathrm{df}=357, p .007 \\ & \text { Maximumeyment level } & t=16.378, \mathrm{df}=358, p .000 \\ \text { Enjoyment } & \text { Opportunity to escape crowd } & t=-5.533, \mathrm{df}=358, p .000 \\ \text { level } & \text { Waximum } & t=7.205, \mathrm{df}=358, p .000 \\ \text { Maximum } & \text { Opportunity to escape crowd } & t=-7.740, \mathrm{df}=358, p .000 \\ \text { number of } & \text { Opportunity to escape crowd } & t=11.117, \mathrm{df}=358, p .000 \\ \text { people to see } & \text { Water activities } & t=15.655, \mathrm{df}=358, p .000 \\ \text { Opportunity to } & \text { Number of boaters } & t=15.082, \mathrm{df}=358, p .000 \\ \text { escape crowd } & \text { Number of people seen } & t=-7.205, \mathrm{df}=358, p .000 \\ & \text { Maximum number of people to see } & t=-11.117, \mathrm{df}=358, p .000 \\ & \text { Enjoyment level } & t=6.816, \mathrm{df}=358, p .000 \\ & \text { Water activities } & t=8.088, \mathrm{df}=358, p .000\end{array}$




\section{Discussion and Conclusion}

Despite each DV is poorly explained by the remaining studied DVs, overall, the results presented in Tables 3 and 4 suggest that all variables are complementing and supporting each other. Therefore, these variables are few of many other barometers that are crucial in evaluating the crowding standard. This however, is not applicable in the case of analysis between IVs. Nevertheless, to this working paper, 'age' should be given an additional attention as the tourism providers are now in serious pursuit of creating tourism products that offer distinctive tourism experience. The idea of tailor-made tourism is further being widespread as a result of the profound economic development (which directly influence the tourism market) as well as various educational programmes that are tourism activitybased. This is further supported by [15] who highlights the significance of understanding the influence level of age on time-varying factors (for instance population and preference), which manipulates the supply-side factors (for example types of resources and destinations attributes).

[16] accentuate the contentious and continuous concerns towards accessibility regulation, usage limitation and resource management; of which, raises '...questions about the efficacy of use limits to actually achieve management goals', in the context of 'time spend'. Within this working paper interest, regardless the negative low $t$ value, emphasis should be given to 'time spend' as it stimulates the distribution of crowding. This is possible as 'time spend' interconnected with ones' leisure time available, by which, directly influences tourism activity engagement. Thus, the understanding of 'time spend' could help in creating a tailor-made tourism activity for the purpose of accommodating and catering different types of targeted tourism market. Of importance, the understanding of 'time spend' will also give a hand in enriching the tourism experience (here, it refers to 'enjoyment level'). Further compounding this issue is the realization that 'time spend' plays a crucial in determining the preferred spaces within a particular tourism spot (for activities engagement), which directly indicating the existing usage and potential carrying capacity of a particular tourism spot [17].

From the perspective of sociology and social psychology, tourism activity (perceived crowding) is something that influenced by norms. More specifically, norms suggest the '...standards that individuals and groups use for evaluating behaviour, social and environmental conditions' [18] where this directly translated into carrying capacity. The results of this working paper indicate higher connection between 'number of boaters' and crowding, compared to 'water activities' and crowding. Within this working paper scope, by adjusting 'number of boaters' will have an impact of crowding distribution but, the adjustment will manipulate the 'enjoyment level'. Therefore, this suggests interlinking 'number of boaters' and 'time spend', looking at [9] findings on tourists' categorization: crowding-averse and crowding-tolerant. By doing so, this will help in balancing the perceived crowd and the accepted crowding ('number of people seen' and 'maximum number of people to see') factors.

\section{Acknowledgement}

This project was funded through a research grant from the Ministry of Higher Education, Malaysia under the Long-Term Research Grant Scheme 2011 [LRGS Grant No. JPT.S (BPKI)2000/09/01/015Jld.4(67)].

\section{References}

1. M. V. Lupke-Schwarz, (2013). A brief history of travel: from elite hobby to mass tourism. Retrieved from http://www.dw.de/a-brief-history-of-travel-from-elite-hobby-to-mass-tourism/a16996047 August 9, 2014

2. B. Neuts \& P. Nijkamp, Crowding perception in a tourist city: a question of preference. Tinbergen Institute Discussion Paper TI 2011-140/3 (2011)

3. G. J. Inglis, V. I. Johnson, \& F. Ponte, Crowding norms in marine settings: a case study of snorkeling on the Great Barrier Reef. Environmental Management 24, 3, 369-381 (1999) 
4. Tourism Intelligence International (2008). The paradigm shift in travel and tourism. Retrieved from http://tourism-intelligence.com/catalog/product_info.php?products_id=265 August 7, 2014

5. X. R. Li \& J. F. Petrick, Tourism marketing in an era of paradigm shift. Journal of Travel Research 46, 235-245 (2007)

6. M. Alexander, Access, tourism and recreation. Management Planning for Nature Conservation, 273-314 (2008)

7. B. Y. Ahn, B. K. Lee, \& S. Shafer, Operationalizing sustainability in regional tourism planning: an application of the limits of acceptable change framework. Tourism Management 23, 1 (2002)

8. R. B. Ditton, A. J. Fedler, \& A. R. Grafe, Factors contributing to perceptions of recreational crowding. Leisure Sciences 5, 4, 273-288 (1983)

9. A. Arnberger, \& W. Haider, Social effects on crowding preferences of urban forest visitors. Urban Forestry \& Urban Greening 3, 125-136 (2005)

10. A. Arnberger, \& C. Brandenburg, Past on-site experience, crowding perceptions and use displacement of visitor groups to Peri-Urban National Park. Environment Management 40, 3445 (2007)

11. Q. Han, B. G.C. Dellaert, W. F. V. Raiij, \& H. J. P. Timmermans, Visitors' strategic anticipation of crowding in scarce recreational resources. Journal of Retailing and Consumer Services 17, 449-456 (2010)

12. S. Doorne, Caves, cultures and crowds: carrying capacity meets consumer sovereignty. Journal of Sustainable Tourism 8, 2, 116-130 (2010)

13. B. Neuts \& P.Nijkamp, Tourist crowding perception and acceptability in cities: an applied modeling study on Bruges. Annals of Tourism Research 39, 4, 2133-2153 (2012)

14. M. A. Tarrant, H. K. Cordell \& T. L. Kibler, Measuring perceived crowding for high-density river recreation: the effects of situational conditions and personal factors. Leisure Sciences: An Interdisciplinary Journal 19, 2, 97-112 (2009)

15. Y. Santana-Jimenez \& J. M. Hernandez, Estimating the effect of overcrowding on tourist attraction: the case of Canary Islands. Tourism Management 32, 415-425 (2011)

16. D. Pettebone, B. Meldrum, C. Leslie, S. R. Lawson, P. Newman, N. Reigner \& A. Gibson, A visitor use monitoring approach on the Half Dome cables to reduce crowding and inform park planning decisions in Yosemite National Park. Landscape and Urban Planning 118, 1-9 (2013)

17. M. A. Tarrant, Variability of the perceived crowding scale: a research note. Leisure Sciences: An Interdisciplinary Journal 21, 2, 157-164 (2010)

18. R. E. Manning, W. A. Valliere \& B. Wang, Crowding norms: alternative measurement approaches. Leisure Sciences: An Interdisciplinary Journal 21, 2, 97-115 (1999) 